14. С чем связан рост производства легких металлов в XX веке?

a) увеличение производства военной техники,

б) увеличение производства электроники и электротехники,

в) развитие авиакосмической промышленности,

г) увеличение разведанных запасов бокситов.

15. Почему возможен разрыв между районами добычи руды и выплавки металла в некоторых производствах цветных металлов?

16. На чем специализируется электронная промышленность Западной Европы?

а) телекоммуникационная аппаратура, вычислительная техника, электронные приборы,

б) навигационная аппаратура, компьютеры и комплектующие к ним,

в) бытовая электроника, медицинское оборудование, комплектующие к компьютерам,

г) компьютеры, телекоммуникационная аппаратура, бытовая электроника.

17. Назовите основные тенденции в размещении автостроения мира (2 ответа):

а) концентрация предприятий в развитых странах, б) перенос сборочных предприятий в развивающиеся страны,

в) перемещение в периферийные и депрессивные районы развитых стран,

г) размещение в железнодорожных узлах.

18. Почему для малых стран Западной Европы характерна узкая специализация машиностроения?

19. Почему сырьевой фактор не оказывает решающего влияния на размещение предприятий АРКП при большой материалоемкости самолетостроения?

a) готовую продукцию этой отрасли сложнее доставить к потребителю, поэтому предприятия размещаются в портовых городах и в крупных железнодорожных узлах для последующей транспортировки,

б) предприятия этой отрасли во всех странах являются государственными, поэтому стоимость перевозки комплектующих деталей не имеет значения,

в) конечная продукция в несколько раз превышает стоимость комплектующих деталей,

г) предприятия этой отрасли размещаются, как правило, вблизи потребителя - в городах с крупными аэропортами, и необходимые детали подвозятся воздушным транспортом непосредственно к сборочным цехам.

\section{НЕКОТОРЫЕ АСПЕКТЫ СОВРЕМЕННОЙ ДЕМОГРАФИЧЕСКОЙ СИТУАЦИИ В САРАТОВСКОЙ ОБЛАСТИ}

\section{С.В. Уставщикова}

\author{
Саратовский государственный университет, \\ кафедра экономической географии \\ E-mail: Sveus 1@yandex.ru
}

Проведенные исследования демографической структуры населения, особенностей миграции, внутриобластных различий демографической обстановки, учет социально-экономического рейтинга региона дают основания сделать вывод о неизбежности дальнейшего процесса депопуляции в области, ухудшения «качества» населения.

Ключевые слова: демографическая ситуация, рождаемость, смертность, миграция, «качество» населения.

\section{Some Aspects of present-day demographical Situation in Saratov Region}

\section{S.V. Ustavshchikova}

The studies of the demographic structure of the population, the characteristics of migration, the intraregional differences in the demographic situation, consideration of socio-economic ranking of the region give the grounds to draw a conclusion about the inevitability of the further process of depopulation in the region, the deterioration of the "quality» of the population.

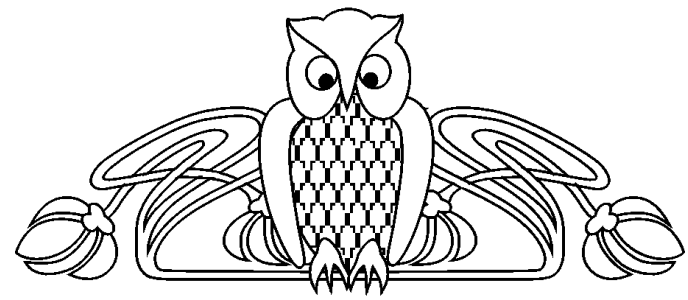

Key words: demographic situation, fertility, mortality, migration, «quality» of the population.

С конца XX в. Российская Федерация вступила в длительную полосу глубокого демографического кризиса. Его причины являются предметом острейшей дискуссии различных исследователей. Каждый регион осуществляет свой «вклад» в демографическое развитие страны, исходя из специфики территории. Главная задача данной статьи - показать некоторые аспекты демографической ситуации в Саратовской области на основе статистической информации и экспертных оценок развития региона, спрогнозировать ситуацию на перспективу.

Население Саратвской области - около 2 \% населения страны. Численность его неуклонно сокращается с 1996 г., когда ее величина составляла 2736,5 тыс. человек. На начало 2009 г. в области проживало 2572,9 тыс. человек [1]. Демографическая ситуация, складывающаяся в любом регионе страны, зависит от социально-экономических, этнографических и демографических факторов, миграционной активности населения. 


\section{Особенности воспроизводства населения в Саратовской области}

Сокращение численности населения области обусловлено его естественной убылью, показатели смертности стали выше показателей рождаемости с 1992 года. Миграционный прирост, который постоянно имеет место, лишь до 1996 г. перекрывал отрицательный естественный прирост населения. С 1997 г. миграционный прирост только в относительно небольшой степени компенсирует отрицательный естественный прирост. Так в 2008 г., который был самым благоприятным в демографическом отношении с начала 2000-х гг. (естественный прирост -4,6 промилле, для сравнения в 2000 г. -8,3), эта компенсация составила лишь 7,5\%, (в 2000 г. этот показатель равнялся 49,6\%, в 2006-22,2\%). Естественная убыль населения в Саратовской области в 2008г. была выше, чем в целом по России $(-2,6 \%$ ) и в Приволжском федеральном округе $(-3,3 \%)$.

По исследованию Л. Рыбаковского, проведшего оценку уровня демографического неблагополучия регионов России (учитывались показатели воспроизводства населения и миграционная составляющая), Саратовская область входит в третью (из пяти) группу демографического неблагополучия. Индекс (коэффициент) демографического неблагополучия в Саратовской области равен 1.746 , в то время как по другим регионам Российской Федерации он варьировал от 1,122 (наилучший показатель) до 2,225 (наихудший) [2]. Иными словами, уровень демографического неблагополучия области значителен.

Применение индексного метода к показателям естественного прироста населения показало, что более высокая, чем в целом по стране, естественная убыль населения в области связана в большей мере с неблагоприятной половозрастной структурой населения и более низкой рождаемостью. Однако, несмотря на сокращение населения, нынешняя демографическая ситуация еще относительно благополучная и масштабы депопуляции относительно невелики по сравнению с тем, что ожидает область уже через несколько лет. Такой прогноз можно сделать на основании анализа современной половозрастной структуры (ПВС) населения (рис. 1). Так, в настоящее время в активный репродуктивный возраст входят относительно многочисленные поколения женщин, родившихся в период заметного повышения рождаемости в стране в 1980 -е годы. В то же время возраста высокой смертности достигают малочисленные поколения родившихся в годы Великой Отечественной войны. Такой возрастной состав населения способствует повышению общих показателей рождаемости, снижению общих показателей смертности и в итоге несколько тормозит естественную убыль населения.

Через несколько лет ситуация изменится кардинальным образом. Активного репродуктивного возраста начнут достигать малочисленные контингенты родившихся в 1990-е гг.: так, по при-

$\square$ Мужчины 四 Женщины

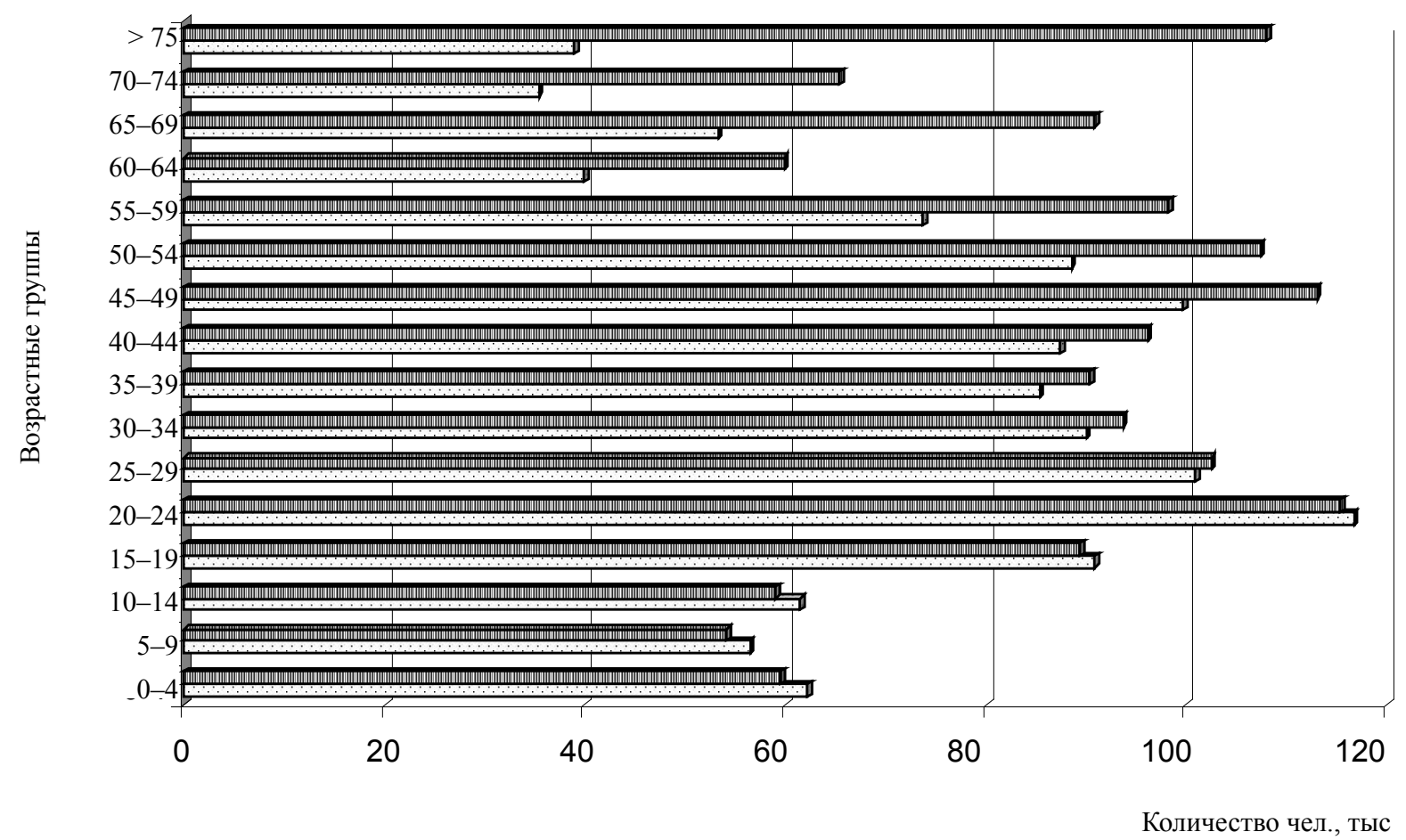

Рис. 1. Половозрастная пирамида населения Саратовской области (на 2008 г.) 
веденной ПВС населения видно, что численность 10-19-летних лиц женского пола на 31,9\% меньше, чем 20-29-летних, а численность тех, кому 0-9 лет, на 23,5\% меньше, чем 10-19-летних, и на 47,9\% меньше, чем 20-29-летних. Потребуется значительное превышение возрастных показателей рождаемости, которое компенсировало бы сегодняшнее сокращение численности женщин активного репродуктивного возраста. Причем это помогает только поддержать общие показатели рождаемости на уровне 2006-2008 годов.

В то же время существенно увеличится доля пожилого населения, так как пожилых возрастов будут достигать сравнительно многочисленные контингенты родившихся в послевоенные годы. Обратимся вновь к современной половозрастной пирамиде: численность 50-59-летних жителей области на 2008 г. была на 33,7\% больше, чем 60-69-летних. Конечно, к сожалению, не все нынешние 50-59-летние саратовцы переживут ближайшие 10 лет, но все равно их поколение останется существенно более многочисленным, чем поколения нынешних 60-69-летних. Это будет способствовать росту общих показателей смертности. Таким образом, грядущее ухудшение возрастной структуры населения Саратовской области приведет (если не будет компенсировано результатами эффективной демографической политики) к заметному росту естественной убыли населения.
Уровень рождаемости в Саратовской области один из самых низких в России. Суммарный коэффициент данного показателя в 2006г. равнялся 1,144 (меньше он был только в Воронежской, Тульской, Ленинградской областях, Санкт-Петербурге, в Республике Мордовия). [3] В настоящее время этот показатель увеличился на 10,7\%, достигнув 1,266 . Есть основания полагать, что это повышение рождаемости было обусловлено реализацией федеральных мер помощи семьям с детьми. Так, материнский (семейный) капитал, который вызвал наибольший резонанс в обществе, привел к повышению показателей рождаемости по вторым и последующим детям.

Одновременно с изменением уровня рождаемости у российских женьщин в последние 10-15 лет происходят существенные изменения в возрастной модели рождаемости, все большая часть рождений смещается к старшим возрастам (рис.2).

Такие изменения в возрастной модели рождаемости показывают, во-первых, увеличение среднего возраста матерей при рождении детей, во-вторых, доли вторых и последующих рождений.

Несмотря на некоторое повышение рождаемости в Саратовской области в 2007 - 2009 гг., ее уровень продолжает оставаться чрезвычайно низким, и задача ее увеличения остается приоритетной при проведении демографической политики.
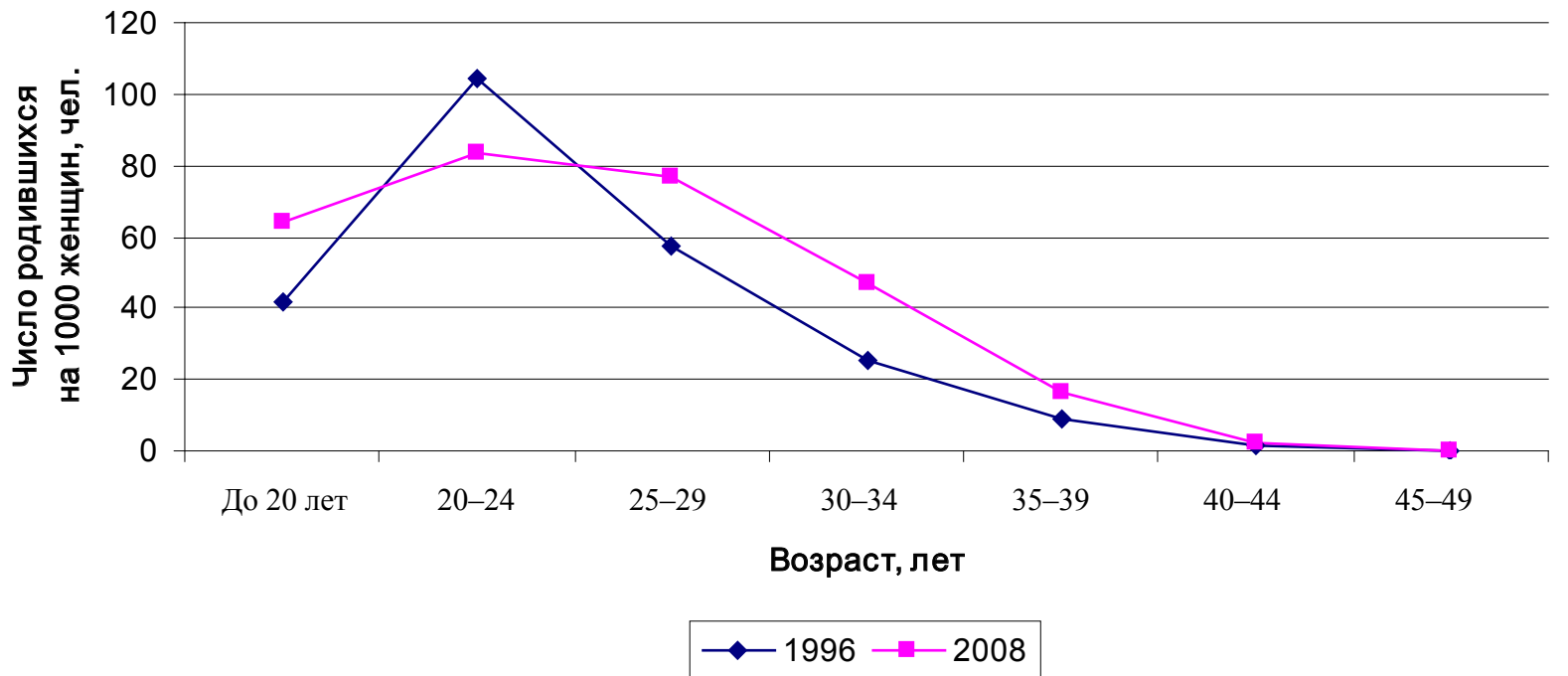

Рис. 2. Возрастные коэффициенты рождаемости за 1996 г. и 2008 г.

\section{Миграционная составляющая демографических процессов}

Миграция имеет значительное прямое и косвенное воздействие на демографическое развитие региона. К демографическим последствиям миграций можно отнести откладывание браков, уменьшение рождаемости, изменение возрастных структур и т. д. Миграционные процессы влияют на «качественные» характеристики населения, тем самым воздействуя на вектор социальноэкономического развития и оценку творческого потенциала региона. Исследования, проведенные А. Пилясовым и О. Колесниковой [4] при оценке творческого потенциала российских региональных сообществ, позволили выстроить все регионы от 0 (худшее значение) до 1 (лучшее значение). Совокупный показатель (сводный индекс креатив- 
ности) рассчитывался как среднее арифметическое следующих частных показателей: индексов таланта, технологий и толерантности. В соответствии с исследованием по данной методике российских регионов Саратовская область имеет сводный индекс креативности $(0,35)$ ниже, чем в целом по Российской Федерации $(0,39)$ на $10,3 \%$. Сложившаяся ситуация может рассматриваться как проблемная, так как креативность регионов напрямую связывается с миграционными процессами. Это подтверждает значимость исследований в области «качественной» характеристики мигрантов в регионе.

По данным рейтингового агентства «Эксперт», Саратовская область занимает 34-е место в стране по уровню своего потенциала, относится к регионам с умеренным инвестиционным риском. По рейтингу финансовой устойчивости регион относится к группе стагнации, по рейтингу экономической устойчивости - к группе умеренного спада, по рейтингу социальной устойчивости - к группе глубокого спада и по комплексному рейтингу антикризисной устойчивости - к группе значительного спада. Напряженность на рынке труда региона повышается [5]. Социальноэкономическое положение области играет значительную роль в динамике миграционных процессов и «качестве» миграции (к этому показателю относятся миграционный прирост, состав мигрантов по возрасту и распределение мигрантов по уровню образования). Анализ статистических данных за последние годы показывает сокращение миграционного прироста в регион, наметился отток населения трудоспособного возраста (преимущественно возрастных групп 16-19 лет, 20-24 года, 25-29 лет), область покидают люди, имеющие высшее профессиональное образование [1]. Обостряется структурное несоответствие рабочей силы, ее образовательных характеристик и рабочих мест. Саратовская область стала терять свой интеллектуальный потенциал. Растет напряженность на рынке труда. Молодые специалисты часто работают не по специальности. Вместе с тем в настоящее время в общей массе мигрантов преобладают неквалифицированные и малоквалифицированные специалисты, что оказывает отрицательное влияние на креативность территории.

Динамика демографических процессов по-разному проявляет себя на внутриобластном уровне, поскольку конкретные субъекты административно-территориального деления Саратовской области (городские округа и муниципальные районы) находятся в неодинаковой не только демографической, но и экономической и социальной ситуации. Налицо мозаичность, асимметрия демографической ситуации. Не существует одинаковой демоситуации в разных районах области. Темпы роста или убыли населения, его структура, характер трудовых ресурсов существенно различаются.
Анализ динамики численности населения и его составляющих (естественного и миграционного движения) проводился с 2002 по 2009 год. К этому времени уже изменились направления миграций из-за смены стрессовых факторов (распад СССР) на экономические, наметились тенденции сокращения смертности и увеличения рождаемости. Тем не менее численность населения области сократилась за эти годы на 95,4 тыс. человек, причем городское население уменьшилось на 55,4 тыс., сельское - на 40,0 тыс. человек. Сокращение городского населения на 76\% происходит за счет областного центра, для которого отрицательными являются показатели и естественного и механического движения. За исключением роста численности населения г. Энгельса, численность других городов и городских поселений сокращается незначительными темпами, либо стабилизировалась (изменения до 1\%), в большинстве случаев в результате внутрирегионального миграционного обмена. Положительный естественный прирост отмечается в Новоузенске, городских поселениях Озинки, Ровное, Свободный, Соколовый [1].

Необходимо обратить пристальное внимание на сокращение сельского населения. Составляя $26 \%$ всего населения области, доля его в сокращении численности - 42\%, причем численность сельского населения 20 районов Правобережья стала меньше на 6,2\%, в то время как 18 Левобережных - на 5,2\%. Правобережье в большей мере охвачено депопуляционными процессами. Показатели естественного воспроизводства населения в Левобережье лучше. Необходимо отметить даже «выход» в последние годы на положительный естественный прирост в пяти районах. Однако наметилась тенденция оттока сельского населения из периферийных районов Левобережья (в том числе и из тех, где отмечается положительный естественный прирост - Новоузенский, Озинский, Перелюбский). На это в значительной мере повлияло реформирование аграрного сектора экономики. Изменение специализации сельскохозяйственных предприятий на юго-востоке области приводит к сокращению занятости и, как следствие, повышению миграционного оттока сельского населения в города и сельскую местность других районов области и за ее пределы.

При сложной демографической обстановке усиливается конкуренция за человеческие ресурсы между городами, областями в стране. Оказавшись дефицитным ресурсом, население будет выбирать более привлекательные для жизни места и мигрировать в регионы с лучшими условиями и высоким уровнем жизни. Но проблема не только в количестве населения, депопуляция резко усиливает значимость его качества. Высшее образование является показателем качества населения. В России завершается переход к массовому высшему образованию. Однако доля занятого городского населения, имеющего высшее образование, доля 
рабочих мест, соответствующих образованию населения, доля высокооплачиваемых мест - пока еще различаются по регионам страны более чем вдвое [6]. Саратовская область пока «проигрывает» в конкуренции за человеческие ресурсы и их качество (отток из области трудоспособного населения с высшем образованием) многим регионам страны. Дальнейшие темпы сокращения численности населения области будут зависеть от социально-экономического развития нашего региона в ближайшие годы, возможности «стягивать» человеческие ресурсы своей внутренней периферии и удерживать собственное население, привлекать высококвалифицированных мигрантов из других регионов страны, рационального использования квалификации и трудовых навыков населения.

\section{Библиографический список}

1. Демографический ежегодник Саратовской области. 2008г: Стат. сб. Саратов, 2009. 180с.

2. Рыбаковский Л. Оценка уровня демографического неблагополучия регионов России: социальные и экономические последствия // Междунар. экономика. 2008. №3. С. 54. 3. Демографический ежегодник Саратовской области. 2006г: Стат. сб. Саратов, 2007. 186c.

4. Пилясов А., Колесникова О. Оценка творческого потенциала Российских региональных сообществ // Вопросы экономики. 2008. № 9. С.50-69.

5. http://www.raexpert.ru/ratings/regions/2009 (дата обращения: 07. 02. 2010)

6. Зубаревич $H$. Кто выиграет конкуренцию за человеческие ресурсы? // Рос. экспертное обозрение. 2008. №1 (24). C.12-16.

\section{ГЕОИНФОРМАЦИОННОЕ КАРТОГРАФИРОВАНИЕ ГЕОЭКОЛОГИЧЕСКИХ РИСКОВ ЭКСПЛУАТАЦИИ НЕФТЯНЫХ МЕСТОРОЖДЕНИЙ (на примере Саратовской области)}

\section{А.В. Молочко}

Саратовский государственный университет, кафедра геоморфологии и геоэкологии E-mail: farik26@yandex.ru

В статье рассмотрены понятия риска в целом, а также геоэкологического риска как одного из проявлений риска эксплуатации нефтяных месторождений в разрезе региональных особенностей территории Саратовской области. Раскрывается схема оценки геоэкологического риска с упором на картографический рисканализ нефтяных месторождений с применением геоинформационных технологий.

Ключевые слова: риск, геоэкологический риск, факторы геоэкологического риска, риск-анализ, нефтяная промышленность, картографический метод риск-анализа, ГИС, картографирование риска, Саратовская область.

Geoecological Risks' geoinformational Mapping of oil-fields Exploitation (Saratov Region as an Example)

\section{A.V. Molochko}

The article represents general concept of the «risk» and concept of geoecological risk as a one of oil-fields' risk exploitation manifestation within the regional features of Saratov region. Also the general chart of risk estimation with emphasis on cartographical risk-analysis of oilfields with application of GIS is disclosed in the article.

Key words: risk, geoecological risk, geoecological risk factors, riskanalysis, oil industry, cartographic method of risk-analysis, GIS, risk mappinig, Saratov region.

Коллективы лаборатории геоинформатики и тематического картографирования и лаборатории

урбоэкологии Саратовского государственного университета им. Н.Г. Чернышевского с 2003 г. на договорных условиях внедряют ГИС-технологии в практику работы ряда служб и подразделений OAO «Саратовнефтегаз». Основным направлением работы в эти годы являлось создание экологически ориентированных геоинформационных систем нефтяного месторождения «ГИС-нефтепромысел» и трасс напорных трубопроводов («ГИС-трубопровод») как универсального средства сбора, обработки и представления информации об экологической обстановке и инженерном обустройстве на нефтепромыслах, трубопроводах и прилегающих к ним территориях [1]. Последнее время коллективами лабораторий и специалистами ОАО «Саратовнефтегаз» особое внимание уделяется проблеме геоэкологического риска эксплуатации нефтегазовых месторождений предприятия.

Понятие «риск» прочно вошло в обиход современного общества. В любой сфере человеческой деятельности можно встретить термин «риск» и близкие ему понятия - «опасность», «ущерб», «рисковая ситуация» и т.п. До сих пор среди исследователей нет общего мнения, ставить ли знак равенства между этими и подобными им терминами. По ГОСТу риск - это вероятность события и его последствия, по руководящим документам - сочетание частоты и последствий определенного опасного события, для ряда ученых - неопределенность предполагаемых событий, которые чаще всего приводят к негативным 